lobe in bovines of the various artificially created and specialised classes these lobules are found to present certain
variations which throw out strong suggestions as to function. In the male animal this lobus sub-occipitalis appears somewhat broadened and squared; the gyri are ample, compli-

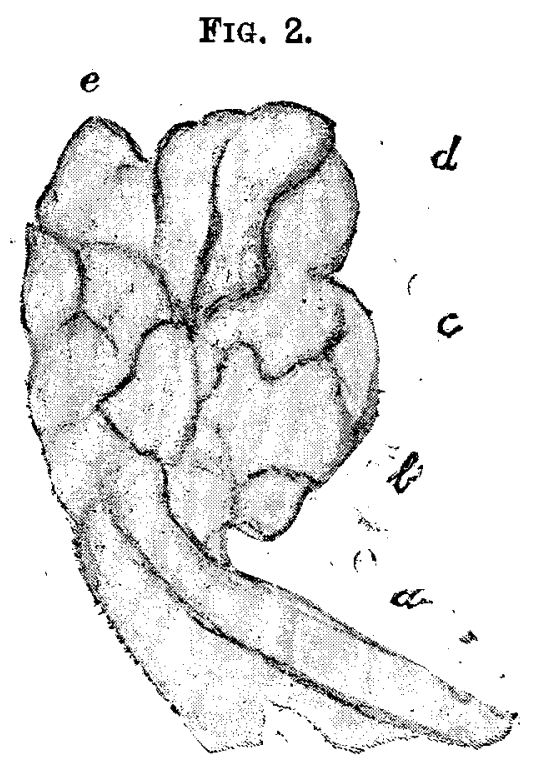

Sub-occipital lobe of right hemisphere of working ox. The ligula is shrunken to the form of a simple conicle. The fusiformis is of simple trefoil shape.

cated, and swelling; the ligula is sharp, strong, and staminal in appearance; and the fusiformis is of ridge-shape or crested.

In the dranght ox the lobe offers a distinct contrast, the posterior extremity being usually rounded or pointed, no longer presenting the squared, expanded, or widened appearance. The lobe is flaccid and anæmic, the ligula is much smaller-reduced to a mere outline, more widely separated from the fusiformis, which now also is smaller and no longer swollen or ridged.

The terms "ligula" and "fusiformis" seem well to define the forms of these lobules in steers and oxen, but do not well apply to those lobules in the brain of the mature male.

-

\section{A CASE OF AGORAPHOBIA, WITH REMARKS UPON OBSESSIONS.}

BY ROBERT JONES, M.D, B.S. LOND., F.R.C.S. ENG., MEDICAL SUPERINTENDENT OF THE LONDON COUNTY ASYLUM, CLAYBURY.

A sINGLE man, aged thirty-nine years, $5 \mathrm{ft} .4 \frac{1}{2}$ in. in height, 8 st. $71 \mathrm{~b}$. in weight, and slightly built, was transferred to Claybury Asylum three years ago from another asylum where he had been admitted a patient about five years previously upon the following medical certificate: " $\mathrm{He}$ is the subject of a morbid dread and fear of something in the way of an accident happening to him and that he cannot move about without seeking protection or assistance from someone. $\mathrm{He}$ is very excitable and particularly anxious in asserting that it is only since an accident that his nervous system has been disorganised. He was brought here [workhouse infirmary] by the police, having given himself up at the police-station because he fancied people were searching for him." The patient's family history revealed that his paternal grandfather was in Bethlem Asylum, that his father was eccentric and parted from his wife, that his maternal uncle was in an asylum, and that his sister suffered from headaches and was peculiar. As to his own previous history, he was always nervous and disliked being alone; he was also somewhat overworked at a business house in the city, where he met with a slight accident by falling from a ladder and striking his head on a counter, receiving some concussion in consequence. He states that he was able to attend to business after that, but felt a dread of walking out of doors, and for some time travelled backwards and forwards by omnibus to avoid crossing streets and passing open places. He states that this uncomfortable sensation grew upon him so that became a terror to him, and he decided to go to America, thinking that he might thus be freed from it. In crossing the sea he never felt anxiety-owing, probably, to the proximity of lateral objects, which gave him security; but it was as bad as ever when he landed and he decided to return, shortly after which he was placed in an asylum, where he remained about five years. He was then discharged, but in three months returned, and he has remained under treatment ever since, about three years. There was no history of syphilis or drink. The patient's present condition is that of a nervous, restless, and fidgety individual, somewhat anxious and impulsive, inclined to slight outbursts of misdirected energy, and he is the very opposite of "calm." He belongs to the psychopathic or neurasthenic type with a marked history, as above related, of a transmitted taint. His looks at times are wild and wandering and his brown eyes are rather prominent. His pupils are dilated but react to light and accommodation. His head, with a bald top, accords with those unexpected measurements often found in the insane, being fall and well shaped. The circumference is $53 \mathrm{~cm}$. ( $21 \frac{1}{2}$ in.), the greatest length with tape is $355 \mathrm{~cm}$. (14 in.), and the width from ear to ear over the crown is $30.5 \mathrm{~cm}$. (12 in.). With callipers the antero-posterior diameter is $19 \mathrm{~cm}$. and the bi-parietal $15.5 \mathrm{~cm}$. His vision upon examination by my colleague, Dr. F. P. Piper, was found to be myopic, glasses of $-45 \mathrm{D}$. bringing the vision of both eyes to $\frac{6}{6}$, but they do not relieve his mental symptoms. There is no astigmatism and the discs present nothing more than slight myopic crescents. There are no vitreous opacities or other retinal changes. Figs. 1 and 2 show his range of vision, as measured by Bischhausen's perimeter, for white light, blue, and red-an almost normal field for each eye. His hearing is preternaturally acute. He conld hear Galton's whistle with the plug at $2 \mathrm{~mm}$. at a distance of $6 \mathrm{ft}$. and he could hear the tick of a watch at almost twice the distance. There was no tympanic abnormality and his throat was normal. His gustatory and olfactory senses seemed to be, if anything, more sensitive than normal, but he has distinct hallucinations of common sensation, believing that he has a needle in his skull which got there after "swallowing the wrong medicine." He talks ramblingly about the "pulsating veins" of his body, \&s. His heart is a "nervous" one, but his lungs and kidneys appeared to be normal and an analysis of the urine in Dr. Mott's laboratory was as follows: quantity in twenty-four hours 1200 c.c, acid, specific gravity 1012 ; total sulphates calculated as $\mathrm{SO}_{3} 0.1328$ per cent. or 1.5936 grammes in 1200 c.c.; aromatic sulphates calculated as $\mathrm{SO}_{3} 0.0151$ per cent., or 0.1812 grammes in 1200 c.c. (the ratio of aromatic sulphates to total sulphates is 1 to $\left.8 \frac{3}{4}\right)$; total phosphates calculated as $\mathrm{P}_{2} \mathrm{O}_{5} 0.069$ per cent., or 0.828 grammes in 1200 c.c.; nitrogenous substances calculated as N 0.940 per cent., calculated as $\mathrm{NH}_{3} \mathbf{0 . 0 5 1}$ per cent., and calculated as proteid matter 5.6588 per cent.; urea 1.5 per cent., or 18 grammes in 1200 c.c.; total solids (solids remaining when urine is dried at $100^{\circ} \mathrm{C}$.) 28.56 grammes in 1200 c.c.; and chlorides calculated as $\mathrm{NaCl} 0.7$ per cent., or 8.4 grammes in 1200 c.c. The patient was occupied by his own request at some clerical work and generally evinced a disinclination to out-door exercise; one day, however, he made one of a party of three for a picnic into Epping Forest. He did not say much about his sensations until it was arranged for this picnic to be repeated, when he described his feelings at length and begged to be excused going further than an avenue of elms leading to Theydon Bois, which he described as "beautiful, for the trees on either side prevented my seeing the open fields and large views beyond." He said that he had always had a dislike to be in "wide places" and that all his life he had avoided them. He states that he has no giddiness on these occasions, although after the concussion referred to he says he saw "St. Paul's [which he was near] turning round and round." He described his feelings at the summer picnic in the open park (where the patients assemble) as those of "acute suffering the whole time." When in the middle of the park he was, he states, overcome with a feeling of intense misery and as if he would have fallen down, although he experienced no headache, giddiness, or dizziness. This feeling, he states, disappears as he gets " near the trees or where there were plenty of people." His feeling is further described as if he should "fall down dead" unless he could 
lay hold of something. It is not the mental dread of the open place or the actual fear of the result of falling that seems to seize him, bat the "miserable suffering it produces." He says he has never been able to stand on any open or high place owing to this feeling of "suffering "-not becasese it brings on giddiness. To stand alone on the edge

FIG. 1.

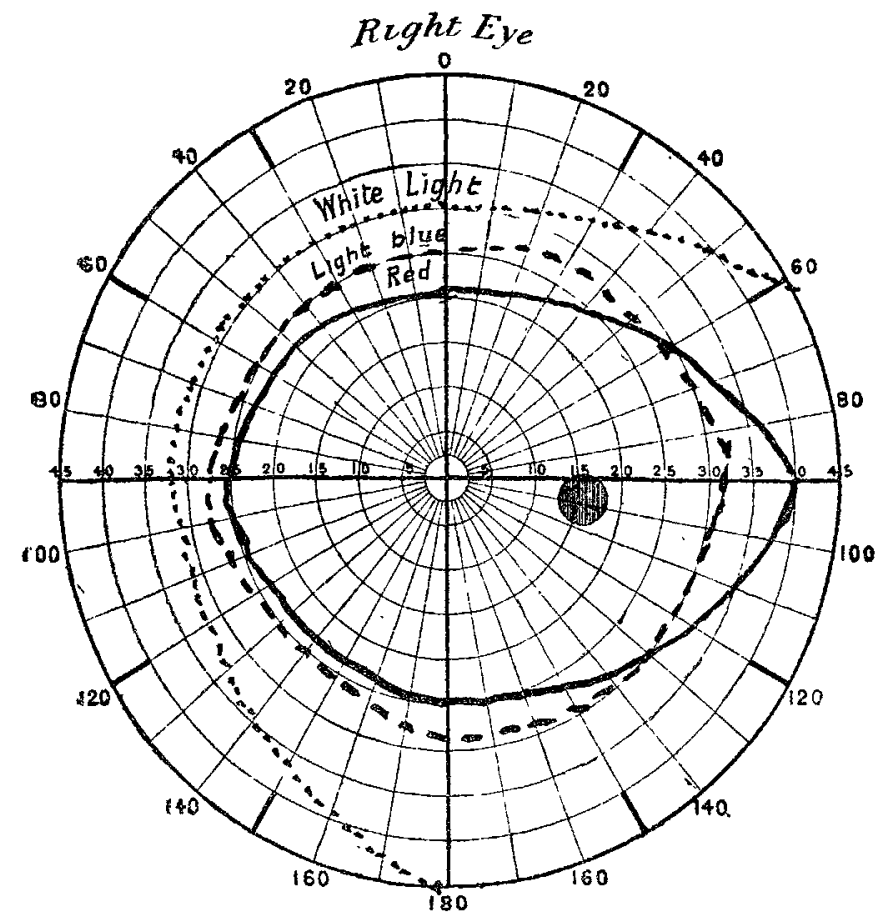

liange of vision for red, blua, and white light for right eye, taken from within, out in the dark.

of a precipice or in the middle of a large plain would give him such agony (using his own words) that "I would rather burn myself to death than do it." $\mathrm{He}$ is fully conscions, he says, of the nnreasonableness of this feeling, but he cannot with an effort of will which makes him "tremble and perspire all over" rid himself of the anguish and tension that he is suffering.

FIG. 2.

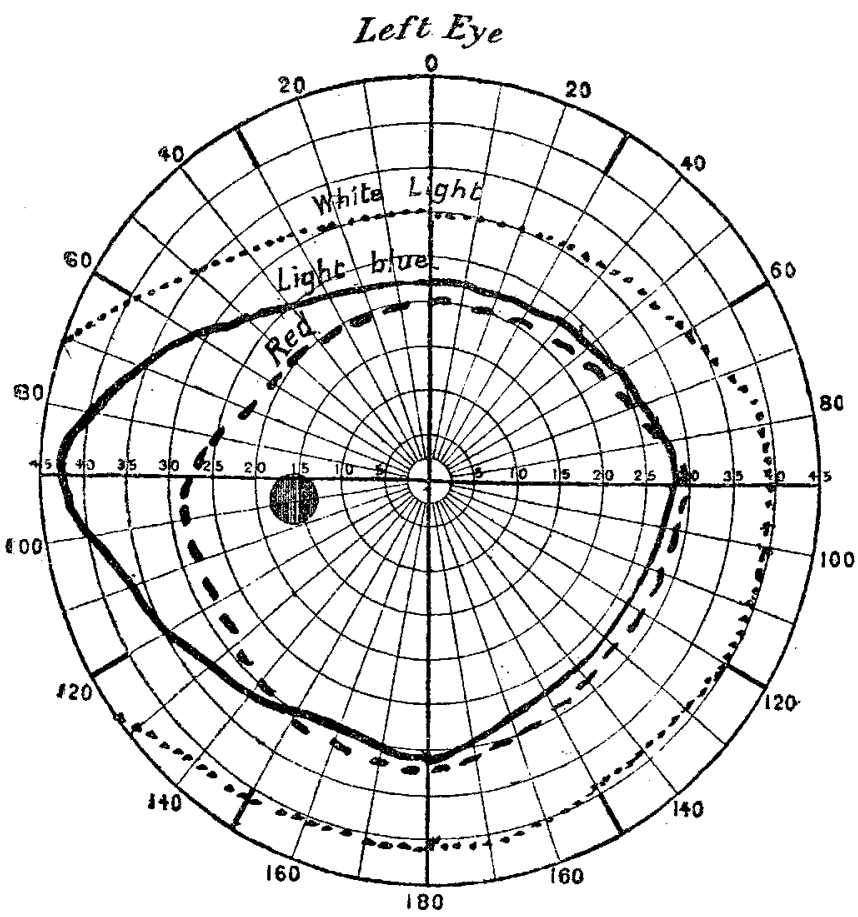

Bange of vision for red, blue, and white light for left eye, taken from within, out in the dark.

There seems to ke a periodicity about this condition and it may (as Nieden has endeavoured to show in similar cases) be epileptic in character as he occasionally wets the bed. Nieden described paroxysms of this sensation as being accompanied with considerable concentric narrowing of the field of vision both for white and colours. This he found to be bilateral and his interpretation suggested that it may bive been of cortical origin and caused by raso-motor spasm of the arteries supplying the visual area of the cuneus. He seems to be supported in the vascular view by the fact that in bilateral (double) hemianopia from disease (? spasm) of the vessels a very small central field of vision is often left, due probably to the half vision centres just perceiving visual impressions. In some cases due to temporary spasm of the vessels and not to permanent destruction of the visual cortex this central remaining part of the field of vision is stated to be correspondingly brighter, although usually there is much diminished acuity. In this case there is no hemianopia and there is comparative symmetry between right and left vision for white light, blue, and red.

Sir Thomas Grainger Stewart, writing to me on Nov. 11th, 1897, stated that he referred to this condition ten or twelve years ago in relation to giddiness and he then regarded agoraphobia as "co-related with cliff or tower giddiness, the patient having somehow learnt to depend for his special equilibration upon visual impressions of lateral objects and the absence of such impressions produces the symptoms." Vision certainly is the most important of the localising senses; our idea of the posture or attitude of our body generally takes the form of a mental picture.

Westphal in 1872 was the first to describe this condition and he characterised it as a neurosis allied to epileptic vertigo. Cordes, Legrand du Saulles, ${ }^{1}$ Ritti, M. le Gros, ${ }^{2}$ and others have described cases. ${ }^{3}$ Maudsley referred to certain so-called "sensitives"-persons easily and deeply affected by impulses so slight as to be out of proportion to the effect produced-who were overcome by a morbid dread. One patient whose case was described by Reichenbach "could not look at an open plain because it made her sick"; another "avoided an open square and preferred to go throngh the alleys rather than cross it." Sir James Crichton Browne, in his address on "Dreamy Mental States," described the overpowering influence which laid Arthur Hugh Clough prostrate after looking over the brow of a beetling cliff at the open sea below and a similar dread is stated to have possessed John Addington Symonds.

Hack Tuke described the case of a lad, nineteen years of age, "a law student who had gained distinction at school and matriculated at the London University, and who met in the course of his reading with the expression-It nas not compatible. Soon after he came across the German wordsIoh liebe es nicht. Now it struck him that the negative in the former sentence preceded, and in the latter succeeded, the most important word. The man began to puzzle himself about negatives in general. Whatever he read raised the question in his mind as to the construction of sentences in which a negative occurred. It became an all-important, allabsorbing problem to him and interfered with his reading and working. The burden of his life was to place the negative in the right order-whatever that might be." The frequent occurrence of a line of poetry or a tune is a familiar instance of the domination over the will of simple words, phrases, or tones. These tyrannies of imperative ideas are called besetments, impellent notions, or obsessions-and obsessions bear the same relation to ideas that impulses do to acts. Obsessions are of many forms and may be considered as falling under $(a)$ intellectual, $(b)$ sensory, or $(c)$ motor varieties. The $(a)$ intellectual include those already quoted, hypnotic suggestions artificially induced, the spontaneous imperious suggestions of the insane, and the quasi-insane conditions of somnambulism; the $(b)$ sensory include an extensive variety according to the sense affected or the combination of various senses by association of ideas-the associative supplementing of ideas; whilst the (c) motor include gestures, grimaces, tricks of posing, carriage, \&c., a familiar one being Dr. Johnson's habit of touching the same object in passing during an occasional walk. Many of these are well known among the inmates of lunatic asylums. These impellent ideas may become a positive torment, growing into persistent fearful ideas and becoming intolerable. There is an absolute inability of the will to inhibit them and they escape all attempts at volitional control.

These cases of imperative ideas are often consistent with sanity in so far as this concerns testamentary capacity and responsibility, but they border closely upon those forms of

1 Peur des Espaces, Gazette des Hôpitaux, 1877-78.

3 I id $187 \%$. Mroch-Pijchologiques, 1885. 
insanity described as abulic ( $\dot{\alpha}, \beta$ ov $\lambda \dot{\eta}-$ will) in whic $h$ violence and vehemence are more often due to loss than to increase of will-power, and in which there occars as a clinical symptom a distinct loss of control of the higher inhibitory centres over thought and action. Moreover, there is an etiology common to the insane and the victims of these fears ; in both there is a taint, both are among the neurotics, their relatives are the neurasthenic and the degenerate, although there may be of their kindred some who are noted for high literary and intellectual attainments. As to the pathology of impellent ideas the presumption that irregular stimulation of isolated cortical centres should cause motor instability on the one hand and vertiginous feelings, disturbed sensations, and emotions-corresponding to the subjective aspect-on the other, would seem to be as favourable a hypothesis as can be advanced according to our present knowledge.

Claybury.

\section{URTICARIA AND ACUTE CIRCUMSCRIBED CUTANEOUS CEDEMA.}

BY H. OPPENHEIMER, M.D. HEIDEL., M.R.C.P. LOND,

THE intimate relation existing between urticaria and that peculiar angio-neurosis known as "acute circumscribed cutaneous cedema" has been a matter of conjecture ever since Quincke first described the latter disease. It has been frequently observed that the same causes which in some individuals call forth a nettle-rash produce in others a peculiar flying cdema which, like the former, is frequently attended with gastro.intestinal disturbance. The connexion between these conditions can be easily understood if it be remembered that the pomphi of urticaria are themselves characterised by local oedematons exudations due to vasomotor influence; but in so far as I know, no cases are on record where both conditions co-existed at the same time in the same individual. Yet I do not think they can be very rare, as in less than three months I had four cases under my care where both urticaria and acute cutaneous odema were present in a well-marked form-unless, indeed, chance has played me that trick which has so frequently been a matter of surprise and has been honoured with the title, "the law of multiplicity of cases." Indeed, I am convinced that both disturbances are absolutely identical, varying only in their manifestations and in the external appearances with the intensity of the process, with the part of the body involved, and with the depth to which the skin is affected. And as I think that the following cases offer some peculiarities in other respects I consider it worth while to publish them.

CASE 1.-A man, aged twenty-five years, came to me on Nov. 20th, 1897, suffering from gonorrhcea. He had been taking sandal-wood oil for the last three days. On getting up on the morning of the 20th he felt an unbearable irritation of the skin, and on inspection he discovered large, well-marked pomphi on the chest, abdomen, and thighs, while the prepnce was enormously swollen. When I saw him in the middle of the day the eruption had spread to the back and arms, the tongue was furred, and I learned that the bowels had not acted for the last two days. I ordered him to discontinue the sandal-wood oil capsules, to take frequent tepid baths, and I gave him a mixture containing bicarbonate of sodium and carbonate of magnesium. In the evening he called again; the rash had reached the face and the eyelids were greatly swollen. I prescribed lead lotion for the eyelids and penis, and the next day the eruption had somewhat subsided. He made a gradual recovery which was complete in about a week.

CASE 2.-This patient was a man, aged thirty-two years, who had been previously under my care for chronic dyspepsia. He came to me on Jan. 4th, 1898. He had had for luncheon on the previous day venison which was rather "high." In the night he awoke with violent itching and noticed some red spots on his abdomen and thighs, while the upper eyelids were very much swollen. The treatment prescribed was as follows: tepid baths, a fall dose of Carlsbad salts, and bicarbonate of potassium in peppermint water. On the 5 th the upper eyelids were free but the lower ones were mucb $s$ wollen; the lips were enlarged to about four times their normal size and the hands were greatly swollen and showed livid discolouration. There were plenty of confluent wheals on the back, buttocks, the extensor surface of the arms and the posterior surface of the legs; a very few isolated ones were on the chest, abdomen, and flexor surface of the arms and anterior surface of the legs. There was no rash on the face. Lead lotion was prescribed. On the 6 th the eyelids were better. There was a plentiful eruption on the face and scanty spots were present on the scalp. The prepuce was very cdematous. On the limbs the order of things was reversed, those parts which previously were comparatively free being much affected anci vice versâ. Salicylate of sodium was given internally while lead lotion was applied to the penis and ichthyol ointment. to the hands. On the $7 \mathrm{th}$ the eruption was even more plentiful than on the day previous. There were enormous masses of wheals on the chest and abdomen. The face was better. The swelling of the hands and prepuce had almost disappeared, but the feet were so much swollen that the patient was unable to put on his slippers. Three grains of calomel and full doses of hydrochloric acid were given. On the 10 th the skin was perfectly free, but there was marked dermography. On the 13 th the patient bad a relapse after partaking freely of roast goose. The eyelids, lips, and feet were very œdematous. There was a free urticaria eruption on the chest and abdomen. On the 17th the slin was normal. There was no dermography.

CAS 3.-A man, aged twenty-three years, came to me on Jan. 17th, 1898. He suffered from cystitis and had been on an exclusive milk diet for the last three days and had taken salicylate of sodium on the 16th. He awoke next morning: with some pains in the wrist and ankles which were very much swollen and livid. The patient thought that he had acute rheumatism. For the last few hours he had felt very troublesome itching and on inspection I discovered a wellmarked nettle-rash which the patient had not noticed before. The bowels were freely open and the tongue was covered with a thick milk fur. I ordered him to stop the galicylate mixture, to take tepid baths, and prescribed lead lotion for external use and internally hydrochloric acid in full doses. On the 18 th the rash was fading away; there were no new eruptions. The ankles and wrists had decreased in size but the prepuce was very much swollen. On the 266 th the skin. had been normal for the last three days; the patient resumed the salicylate of sodiam, and on the very next day the rash reappeared even more plentifully than before. The trunk and limbs were almost completely covered with urticaria there were isolated pomphi on the face and scalp. The eyelids, lips, and prepuce showed cedematous infiltration. The previous treatment was resumed. On Feb. 1st the skin was perfectly normal and no more salicylate having been taken it has remained so.

CASE 4.-The patient was a woman, aged twenty-eight years, whom I saw on Jan. 21st, 1898. She had been previously healthy except for habitual constipation. On the 19th she had partaken of mussels and she awoke next night with a fearful initation of the skin, and on getting up in the morning discovered that her whole body except the face was covered with an eruption which proved to be urticaria and that the eyelids, hands, and feet were very much swollen. The bowels had not acted for the last three days; the tongue was clean. The eyelids were very pale and the hands and feet were dark livid. Warm baths, lead lotion for the eyelids, and ichthyol ointment for the hands and feet were preseribed and internally Carlsbad salts and hydrochloric acid. Or the 23rd the bowels bad not yet acted. The rash had somewhat decreased but had spread to the face and scalp. The eyelids and hands were free but the feet were still swollen and livid. The nymphæ were odematous and transformed into bags of the size of a hen's egg. The front and sides of the neck were blown up with serous transudation, so that the neck had the appearance of being surrounded by a thick collar. Calomel (two doses of three grains each) and hydro. chloric acid continued in increased doses were prescribed. On the 24th there was less irritation. The rash was still visible. The swellings were diminishing in size. One dose of calomel (two grains) was prescribed. On the 27 th the nettle-rash disappeared but the neck and feet were still somewhat enlarged. On Feb. 3rd the skin was perfectly normal.

Adamson-road, N.W. 